\title{
FORMAÇÃO DE PROFESSORES DE EDUCAÇÃO INFANTIL: UM LEVANTAMENTO BIBLIOGRÁFICO
}

\author{
Vanessa Helena Seribelli, Cinthia Magda Fernandes Ariosi
}

Universidade Estadual Paulista Julio de Mesquita Filho - UNESP, Programa de Pós Graduação Educação, Presidente Prudente, SP. E-mail: vanessa_seribelli@hotmail.com

\section{RESUMO}

O presente trabalho dialoga sobre as pesquisas realizadas no campo da formação de professores, com foco na Educação Infantil. Tem como principal objetivo, compreender os avanços nesse campo de pesquisa, entre os anos 2000 à 2016. Para isso, a metodologia utilizada insere-se na abordagem quanti-qualitativa, utilizando como procedimento para a coleta de dados o levantamento bibliográfico nas bases de dados do Caderno CEDES e ANPAE. A fundamentação teórica, respalda-se em autores como Libâneo (2001), André (2010), Saviani (2009), Nóvoa (1992), entre outros. Autores que auxiliam na compreensão da temática formação docente. Os resultados apontam avanços quantitativos no campo de pesquisa, ao mesmo tempo, a necessidade de avançar no campo da prática da Educação Infantil, a fim de que este nível de ensino cumpra seu papel: trabalhar com as potencialidades da criança objetivando seu desenvolvimento seja pleno. Palavras-chave: Formação de professores, Educação infantil, Levantamento bibliográfico.

\section{TRAINING OF TEACHERS OF CHILD EDUCATION: A BIBLIOGRAPHICAL SURVEY}

\begin{abstract}
This paper discusses the research carried out in the field of teacher education, focusing on Early Childhood Education. Its main objective is to understand the advances in this field of research between 2000 and 2016. For this, the methodology used is part of the quantitative-qualitative approach, using as a procedure for data collection the bibliographic survey in the databases of the Caderno CEDES and ANPAE. The theoretical basis is supported by authors such as Libâneo (2001), André (2010), Saviani (2009), Nóvoa (1992), among others. Authors who help in the understanding of teacher training. The results point to quantitative advances in the field of research, at the same time, the need to advance in the field of the practice of Early Childhood Education, so that this level of education fulfills its role: to work with the potentialities of the child with a view to its development is full.
\end{abstract}

Keywords: Teacher training, Child education, Bibliographic survey. 


\section{INTRODUÇÃO}

Este trabalho é um levantamento bibliográfico sobre a formação de professores, com foco no seguimento Educação Infantil. O interesse em desenvolvê-lo, surgiu das discussões realizadas no Grupo de Estudos e Pesquisas sobre a Primeira Infância (GEPPI) da Universidade Estadual Paulista "Júlio de Mesquita Filho" - UNESP, campus de Presidente Prudente.

Instigadas pelas leituras, em especial, Barbosa (2006), que discute sobre a educação infantil como um campo de pesquisa recente, o questionamento que nos provocou foi: $O$ que revelam as produções cientificas acerca da formação de professores na educação infantil? Buscamos então, compreender a constituição do campo de formação de professores, a necessidade da formação inicial e continuada, as condições do trabalho docente na sociedade contemporânea e a trajetória histórica da Educação Infantil no Brasil.

$\mathrm{Na}$ busca de compreender essas questões, embasamos nossa fundamentação teórica em autores como Libâneo (2001), André (2010), Saviani (2009), Nóvoa (1992), entre outros.

Nessa perspectiva, o objetivo desse estudo é compreender o que os trabalhos produzidos entre os anos 2000 à 2016 no Brasil, dizem sobre o campo da formação de professores, com foco na educação infantil. A investigação é de caráter quanti-qualitativa e o instrumento de coleta de dados utilizado foi o levantamento bibliográfico realizado nas bases de dados Caderno CEDES e Associação Nacional de Política e Administração da Educação (ANPAE).

Cabe salientar que cada base de dados tem suas especificidades em relação a busca e seus instrumentos. Porém, as palavras-chave que nortearam as buscas foram as mesmas: Formação de professores, Trabalho docente e Educação Infantil.

No desenvolvimento do texto, apresentamos a fundamentação teórica, os conceitos e autores que pautaram nossas análises, a constituição do campo da formação de professores, como essa formação se concretiza no campo da educação infantil e a importância da formação inicial e continuada. Exibimos a metodologia, detalhando os caminhos percorridos na investigação e evidenciando as abordagens utilizadas e os instrumentos de coleta e análise de dados.

As análises têm como foco os temas: formação inicial, formação continuada e trabalho docente na educação infantil. De acordo com o tema, subdividimos estes em subtemas e analisamos por base de dados. Por fim, concluímos nossas análises e fazemos apontamentos para aqueles que pretendem colaborar com o campo de formação de professores, numa perspectiva crítica e contextualizada.

As constatações deste estudo, nos permite concluir, que houve evolução teórica no campo das políticas públicas para a educação infantil, entretanto, existem indagações persistentes sobre as práticas educativas presentes nas instituições, haja vista que estas parecem não ir ao encontro do que é orientado nos documentos.

Sobretudo, ressaltamos a função social da pesquisa, que através de seus apontamentos pode promover transformações favoráveis ao desenvolvimento humano, ajudando a obter possíveis respostas a questões que se levantam em torno da educação nas suas diferentes etapas de ensino e nos seus diferentes aspectos.

\section{METODOLOGIA}

A expressão método é definida do grego metá (através de) e adós (caminho), ou seja, o caminho pelo qual deseja-se encontrar a solução/resposta do problema que se propõe na pesquisa.

Através do termo método, é possível explicar o significado de metodologia como um processo que objetiva atingir um determinado fim ou para atingir o conhecimento, assim, a metodologia científica trabalha com métodos científicos, que têm como objetivo coletar dados e realizar uma rigorosa investigação sobre um tema, de modo que um resultado ou um fim seja alcançável. 
Bourdieu (1999) indica que a escolha do método não deve ser rígida, mas sim rigorosa, ou seja, o pesquisador não necessita seguir um método só com rigidez, mas qualquer método ou conjunto de métodos que forem utilizados devem ser aplicados com rigor. Sendo assim, é importante destacar, que esse trabalho aborda elementos quantitativos e qualitativos, caracterizando-se segundo Tashakkori e Teddlie (2010), como pesquisas de métodos mistos, onde são combinados os diferentes aspectos quantitativos e qualitativos com o foco voltado para o problema de pesquisa, cujas peculiaridades determinarão as características metodológicas eleitas para o desenvolvimento do processo investigativo.

Como dito anteriormente, a presente pesquisa trata-se de um levantamento bibliográfico. Sobre os passos de uma pesquisa bibliográfica Medeiros (2000) diz que

A pesquisa bibliográfica compreende: escolha do assunto, elaboração do plano de trabalho, identificação, localização, compilação, fichamento, análise e interpretação, redação. $\mathrm{O}$ assunto será delimitado e preciso; ao geral, amplo, será preferido o restrito. Exige, portanto, que seja escolhido assunto condizente com a capacidade do pesquisador, de acordo com suas inclinações e gosto pessoais. Outros fatores que devem ser considerados: tempo para realizar a pesquisa e existência de bibliografia pertinente ao assunto. Evitem-se assuntos pouco aprofundados ou sobre os quais pouco foi escrito, isto é, cujo conhecimento é ainda duvidoso e superficial. Depois de escolhido o assunto, passase para sua delimitação, o que vem a constituir-se no tema. Favorecem à delimitação do assunto: o uso de adjetivos explicativos e restritivos, de complementos nominais, de adjuntos adverbiais. Exemplos: Redação escolar no Ensino Fundamental. Experiências no ensino de redação para o Ensino Médio. Normas Gerais para os Trabalhos Científicos nos Cursos de Graduação Após o estabelecimento do tema, que é o assunto devidamente delimitado, passa-se à fase de leitura e fichamento. Há autores que recomendam como passo seguinte o estabelecimento de um plano provisório. Evidentemente, com o transcorrer da pesquisa, o plano pode ser alterado. Para a elaboração do plano, leve-se em conta que deverá ter: introdução (formulação do tema, importância dele, justificativa da pesquisa, metodologia a ser empregada); desenvolvimento (fundamentação lógica do trabalho, explicação do tema, discussão, demonstração). 0 desenvolvimento deve ser dividido em tópicos. Finalmente, a conclusão exige que tudo seja sintetizado (p. 40-42).

Corroborando com as ideias do autor, os passos da pesquisa foram realizados sistematicamente, com o objetivo de encontrar e analisar as produções que abarcassem o tema Formação de professores e trabalho docente na perspectiva da educação infantil. Sendo assim, foram consultadas as seguintes bases de dados: Caderno CEDES e ANPAE.

Esclarecemos que, ao utilizarmos o tema formação inicial e continuada (juntos) trata-se de trabalhos que dialogavam sobre programas em que os professores em exercício na educação básica recebiam sua primeira formação em nível superior ou estudos em que havia parceria entre a universidade e a educação básica, de maneira que estudantes de formação inicial e professores da educação básica se beneficiavam mutuamente.

Considerando que cada base de dados tem sua configuração própria, os caminhos percorridos na busca dos trabalhos aconteceram da seguinte maneira:

\section{CADERNO CEDES - CENTRO DE ESTUDOS EDUCAÇÃO E SOCIEDADE}

A busca por trabalhos nesse site aconteceu por meio da pesquisa traduzida em língua portuguesa e seguiu os seguintes passos:

- Acesso a base de dados online;

- Identificação dos números contemplados dentro do período estabelecido (2000 à 2016);

- Acesso individual de cada periódico;

- Leitura de títulos, resumo e artigos completos para seleção dos trabalhos dentro da temática. 
Após acessar os periódicos publicados no período, encontramos os seguintes resultados:

Tabela 1. Temáticas encontradas no Caderno CEDES

\begin{tabular}{l|l}
\hline Temática Abordada & Total de Publicações \\
\hline Trabalho docente & 3 \\
\hline Formação inicial e continuada & 2 \\
\hline Formação continuada & 2 \\
\hline Formação inicial & 0 \\
\hline
\end{tabular}

Fonte: Sistematizado pelas autoras a partir do mapeamento nas bases de dados do caderno CEDES

Dessa maneira, ao avaliar a frequência relativa de trabalhos produzidos acerca das temáticas, verifica-se que ao longo de dezessete anos, apenas sete trabalhos foram produzidos contemplando a formação de professores e o trabalho docente na educação infantil, em um montante de 332 produções. Conclui-se então, que a representatividade destes trabalhos é de apenas $2,1 \%$.

Nota-se que, as pesquisas voltadas para a Educação Infantil se mostram, ao longo do período, debruçadas mais especificamente ao trabalho docente. Embora a temática apresente sua relevância quanto a valorização do professor, bem como a construção da sua identidade, a formação inicial é, também, fator decisivo no que tange a qualidade da educação. $O$ fato de apenas um trabalho contemplar a temática é bastante preocupante, haja vista que a formação inicial tem o papel fundamental no desenvolvimento do professor e sua qualidade vem sendo questionada (PIMENTA, 2014).

Com o intuito de analisar mais profundamente o que de fato as pesquisas pretendem abordar ao tratar do assunto, os achados foram agrupados em subtemas. Dentro da temática trabalho docente, três subtemas foram encontrados: Identidade docente, Valorização/condições de trabalho e Padronização do trabalho docente. A temática formação inicial e continuada, abordou dois subtemas: O olhar para o "eu" professor e a Qualidade da formação inicial na construção da autonomia para a formação continuada. Em relação ao tema formação continuada, os subtemas encontrados foram: Perfil do professor e Políticas públicas.

\section{ANPAE - ASSOCIAÇÃO NACIONAL DE POLÍTICA E ADMINISTRAÇÃO DA EDUCAÇÃO}

No site da ANPAE (Associação Nacional de Políticas e Administração da Educação) foram selecionados dois eventos para levantamento dos trabalhos relacionado ao tema, o Simpósio Brasileiro de Políticas e Administração e Congresso Ibero-Americano/Congresso Luso-Brasileiro. Haviam disponíveis online apenas trabalhos a partir do ano de 2007 referente ao Simpósio, sendo que este evento acontece a cada dois anos, e a partir de 2010 referente ao Congresso, sendo que este evento também ocorre a cada dois anos.

O site de cada evento tem suas particularidades, porém nenhum disponibiliza ferramenta de busca própria, desse modo foi necessário utilizar a ferramenta de busca disponível no navegador, ativada pelo comando "CTRL + F". Essa ferramenta é muito útil, porém tem suas limitações, ela busca palavras idênticas em qualquer parte da página. Assim, o foco das buscas foi nos títulos dos trabalhos e o número de palavras-chaves utilizadas foi ampliado. Foram usadas as palavras: Educação Infantil, formação de professores, formação, prática docente, trabalho docente, trabalho e prática. Em caso de dúvida em relação ao título, foi aberto o trabalho completo e visto se correspondia ao nível de ensino (educação infantil) e ao tema (formação de professores e trabalho docente), a partir da leitura do resumo e de nova busca das palavras.

A pesquisa foi feita em todos os eixos de trabalho, nos anos em que há esse tipo de divisão. No ano de 2015, o Simpósio foi classificado por Grupo de trabalho (GT), e também foram verificados todos. 
Quando o evento dividia as apresentações em Comunicações, Relatos e Pôsteres, a pesquisa foi realizada em todos estes, porém em relação aos pôsteres, as publicações encontradas foram do tipo resumo expandido. Embora alguns deles façam parte do tema, em seu interior traziam poucas informações relevantes à pesquisa, por esse motivo, foram descartados. A tabela abaixo mostra as temáticas encontradas.

Tabela 2. Temáticas Abordadas na ANPAE

\begin{tabular}{l|l}
\hline Temática Abordada & Total de Publicações \\
\hline Trabalho docente & 5 \\
\hline Formação inicial e continuada & 5 \\
\hline Formação continuada & 2 \\
\hline
\end{tabular}

Fonte: Sistematizado pelas autoras a partir do mapeamento nas bases de dados da ANPAE

Dentro do tema trabalho docente, foram encontrados quatro subtemas: Representações sociais, Plano de carreira, Condições de trabalho e Políticas municipais. Em relação ao tema formação inicial, encontramos quatro subtemas: Qualidade da formação para a prática, Legislação/história, Currículo do curso de Pedagogia, Saberes e Identidade do Pedagogo. Por fim, a temática formação continuada, abordou dois subtemas: Currículo/saberes docentes e Práticas docentes.

\section{DISCUSSÃO}

A partir das análises realizadas no Caderno CEDES, pode-se concluir que, muito a tem a se revelar no campo da formação de professores e trabalho docente na educação infantil. Para tanto, é preciso que as instituições de ensino que fomentam as pesquisas se debrucem na área, uma vez que as novas concepções de criança e infância exigem do professor, especificidades para lidar com este nível de ensino. Para que a educação infantil cumpra seu papel de maneira plena, é preciso quebrar barreiras a fim de que o campo da prática avance em consonância com o campo da teoria.

Das análises realizadas no banco de dados da ANPAE, as cinco investigações sobre trabalho docente, foram publicadas depois de 2010, isto é, há menos de dez anos. Embora sejam questões que interferem no trabalho da classe, as pesquisas no Brasil são feitas dentro das universidades e, neste caso, predominantemente na região Sul e Sudeste do país.

Outra questão importante e que merece ser ressaltada, é a lacuna existente entre a educação básica e o ensino superior. É possível inferir, através das análises dos trabalhos, que, os processos de reflexão e pesquisa para autoformação e formação continuada, se mantém na bipolaridade teoria e prática, onde a universidade detém o conhecimento e transfere para aqueles que a colocarão em prática.

De acordo com a LDB/1996 em seu artigo 43, a educação superior tem por finalidade:

I - estimular a criação cultural e o desenvolvimento do espírito científico e do pensamento reflexivo;

II - formar diplomados nas diferentes áreas de conhecimento, aptos para a inserção em setores profissionais e para a participação no desenvolvimento da sociedade brasileira, e colaborar na sua formação contínua;

III - incentivar o trabalho de pesquisa e investigação científica, visando o desenvolvimento da ciência e da tecnologia e da criação e difusão da cultura, e, desse modo, desenvolver o entendimento do homem e do meio em que vive[...].

(BRASIL, 1996).

Diante das investigações realizadas e das reflexões acerca do que traz a LDB/1996 no artigo supracitado, o questionamento que nos instiga é: há diferenças entre professor e pesquisador?

Ousamos inferir, apoiadas em Fazenda (2008), que não deveria existir ambiguidades entre o professor pesquisador (aquele que na maioria das vezes é o professor universitário) e o 
professor de educação básica, mais especificamente, o professor de educação infantil. Segundo Ivani Fazenda (2008).

Aprender a pesquisar, fazendo pesquisa, é próprio de uma educação interdisciplinar, que, segundo nossos dados, deveria se iniciar desde a pré-escola. Uma das possibilidades de execução de um projeto interdisciplinar na universidade é a pesquisa coletiva, em que exista uma pesquisa nuclear que catalise as preocupações dos diferentes pesquisadores, e pesquisas-satélites em que cada um possa ter o seu pensar individual e solitário. $\mathrm{Na}$ pesquisa interdisciplinar, está a possibilidade de que cada pesquisador possa revelar a sua própria potencialidade, a sua própria competência. (FAZENDA, 2008, p. 10).

Nessa linha de pensamento, as análises mostram que, o professor é colocado num papel subalterno, tendo que colocar em prática aquilo que lhes ensina os pesquisadores. Estes, por sua vez, não possuem (em sua maioria) a prática da sala de aula, o que torna essa relação cada vez mais assimétrica, refletindo na qualidade das práticas educativas.

Fica evidente então, a necessidade de efetivação de uma prática onde, universidade e escola pública trabalhem juntos, buscando a melhor forma possível de superar os desafios constantes da profissão docente.

\section{RESULTADOS E CONCLUSÕES}

Com os resultados obtidos através do levantamento bibliográfico, realizado nas bases de dados da ANPAE e Cadernos CEDES ao longo dos dezesseis anos, no respectivo período de 2000 a 2016, sobre a Formação de Professores e Trabalho Docente na Educação Infantil, foi possível concluir, sem a pretensão de esgotar o assunto, mas com intuito de contribuir para o campo, que poucas discussões e reflexões teóricas e práticas foram realizadas sobre essa temática, nessa etapa de ensino.

Em relação à quantidade reduzida de pesquisas encontradas, destacamos como necessário que essa temática seja mais investigada, pois dada a importância que essa etapa de ensino representa na vida das crianças e em seu desenvolvimento, e o papel do professor na efetivação do ensino que nela é oferecido, consideramos fundamental os indicativos que as pesquisas podem trazer à tona, de forma a contribuir para a identificação de aspectos que afetam diretamente a qualidade do ensino, assim como mudanças e transformações necessárias para o sucesso da criança nas etapas subsequentes de seu processo de escolarização.

Ressaltamos que, as habilidades desenvolvidas na primeira infância têm papel fundamental no desenvolvimento humano. Com isso, observa-se um movimento político e social no campo teórico a esse respeito. Entretanto, no que diz respeito às práticas no interior das escolas envolvendo os professores deste nível de ensino, no campo da formação e do trabalho docente, as pesquisas evidenciam poucos avanços em relação à temática. Dessa maneira, no campo da prática, muito tem que se avançar na Educação Infantil a fim de que este nível de ensino cumpra seu papel: trabalhar com as potencialidades da criança objetivando seu desenvolvimento seja pleno.

\section{REFERÊNCIAS}

ANDRÉ, Marli. A pesquisa sobre formação de professores: contribuições à delimitação do campo. In: DALBEN, Ângela I.L.F. et al. Didática: convergências e tensões no campo da formação e do trabalho docente. Belo Horizonte: Autêntica, 2010. p. 273-283.

ANDRÉ, Marli. A produção acadêmica sobre formação de professores: um estudo comparativo das dissertações e teses defendidas nos anos 1990 e 2000. Formação Docente - Revista Brasileira de Pesquisa sobre Formação Docente, v. 1, n. 1, p. 41-56, ago./dez. 2009. Disponível em: . Acesso em: 
5 abr. 2010.

BARBOSA, M.C.S. Por amor e por força: Rotinas na educação infantil. Porto Alegre: Artmed, 2006. BRASIL. Conselho Nacional de Educação. Resolução CNE/CEB no 5/2009. Diretrizes Curriculares Nacionais para a Educação Infantil. Brasília, DF: Diário Oficial da União, 18 dez de 2009.

BRASIL. Constituição da República Federativa do Brasil: promulgada em 05 de outubro de 1988. Organização do texto por Juarez de Oliveira. 4. ed. São Paulo: Saraiva, 1990. 168 p. (Série Legislação Brasileira).

BRASIL. Lei n. 9.394, de 20 de dezembro de 1996. Estabelece as Diretrizes e Bases da Educação Nacional. Brasília: MEC, 1996. Disponível em: < http://www.planalto.gov.br/ccivil_03/Leis/L9394.htm >. Acesso em: 23 mar 2008.

BRASIL. Referencial Curricular Nacional para Educação Infantil. Brasília: MEC / SEF, 1998.

BOURDIEU, P. A miséria do mundo. Tradução de Mateus S. Soares. 3 ed. Petrópolis: Vozes, 1999. CANÁRIO, R. A escola: das "promessas" às "incertezas". Educação Unisinos, Rio Grande do Sul, v.12, n.2, p. 73-81, mai./ago.2008. Disponível em http://revistas. unisinos.br/index.php/educacao/article/view/5309/2556.Acesso em 31 jan.2017.

CUNHA, M. I. O tema da formação de professores: trajetórias e tendências do campo na pesquisa e na ação. Educação e Pesquisa, São Paulo, v.39, n.3, p.609-625, jul./set. 2013. Disponível em: http://www.scielo.br/pdf/ep/v39n3/aop1096.pdf. Acesso em: 03 fev. 2017.

FAZENDA, Ivani C. A. (org.) Didática e interdisciplinaridade. 13ạ ed. São Paulo: Papirus, 2008.

GATTI, B. A.; BARRETTO, E. S. S. Professores do Brasil: impasses e desafios. Brasília: Unesco, 2009.

GATTI, B. A.; BARRETO, E. S.; ANDRÉ, M. E. D. de A. Políticas docentes no Brasil: Um estado da arte. Brasília: UNESCO/MEC, 2011.

GATTI, B. A.; BARRETTO, E. S. S. Professores do Brasil: impasses e desafios. Brasília: Unesco, 2009.

LIBÂNEO, J.C. et al. Educação escolar: políticas, estrutura e organização. São Paulo: Cortez, 2001.

MANCEBO, D. Agenda de Pesquisa e opções Teórico-Metodológicas nas investigações sobre Trabalho Docente. Educ. e Soc., Campinas, vol. 28, n. 99, p.466-482.mai/ago. 2007.

MEDEIROS, J. B. Redação Científica: a prática de fichamentos, resumos, resenhas. São Paulo: Atlas, 2000.

NÓVOA, Antonio. Profissão: professor. Portugal, Porto Ed., 1991.

NÓVOA, António (Coord.). Os professores e sua formação. Lisboa: Dom Quixote, 1992.

PIMENTA, S.G. A formação de professores para a educação infantil e para os anos iniciais do ensino fundamental: análise do currículo dos cursos de pedagogia de instituições públicas e privadas do estado de São Paulo. ENDIPE, 2014. 
TASHAKKORI, A.; TEDDLIE, C. Putting the human back in "Human Research Methodology": the researcher in mixed. Journal of Mixed Methods Research, v. 4, n. 4, p. 271-277, 2010. https://doi.org/10.1177/1558689810382532 